RESEARCH REPORT

\title{
Socioeconomic status over the life course and stages of cigarette use: initiation, regular use, and cessation
}

\author{
S E Gilman, D B Abrams, S L Buka
}

See end of article for
authors' affiliations
........................
Correspondence to:
Stephen E Gilman, Centers
for Behavioral and
Preventive Medicine,
Brown Medical School and
the Miriam Hospital,
CORO Building, Suite 500,
1 Hoppin Street,
Providence, Rhode Island
O2903, USA;
sgilman@hsph.harvard.edu

Accepted for publication 19 March 2003
J Epidemiol Community Health 2003;57:802-808

Study objective: To investigate the association between multiple indicators of socioeconomic status (SES) over the life course and three stages of cigarette use: initiation, regular use, and cessation.

Design: Prospective birth cohort study.

Setting: Providence, Rhode Island.

Participants: Subjects $(n=657)$ aged 30 to 39 were offspring of participants in the Brown University cohort of the United States National Collaborative Perinatal Project started in 1959.

Main results: A significantly increased risk of smoking initiation was observed among people from lower socioeconomic backgrounds. Low SES in childhood also increased the risk for progression to regular smoking, and was associated with a reduced likelihood of smoking cessation. Progression to regular smoking and smoking persistence were also associated with lower adult SES.

Conclusions: Socioeconomic conditions over the life course accumulate to produce increased rates of smoking uptake and reduced rates of cessation among lower SES people. Addressing SES gradients in smoking will require persistent and extended intervention over multiple life stages.
$\mathrm{T}$ he concentration of cigarette smoking among people of lower socioeconomic status (SES) is well established. ${ }^{1-4}$ The SES gradient in smoking-that is, the increasing prevalence of smoking with decreasing SES-has persisted for several decades despite aggregate decreases in smoking prevalence in the population as a whole. In fact, recent epidemiological data suggest that socioeconomic inequalities in smoking have been widening. ${ }^{5-7}$ These inequalities are not only a United States phenomenon; rather, they exist globally $^{8-16}$ and appear to be widening globally. ${ }^{17-19}$ Addressing the SES gap in smoking will be critical for achieving further reductions in smoking at the population level $^{2}{ }^{7}$; towards this end, it is important to understand the development of socioeconomic differentials in the initiation and continuation of smoking.

Prior research on SES differences in smoking has often relied on assessments of prevalent or lifetime smoking, 45792021 thereby obscuring the transitional nature of cigarette use by conflating the processes of initiation, continuation, and cessation. It remains unknown whether the determinants for smoking uptake mirror those for cessation. In addition, because the stages of cigarette use are patterned across the life course, with the majority of initiation occurring in adolescence, ${ }^{22-25}$ it is important to determine whether socioeconomic differentials in smoking accumulate with age.

Investigations into socioeconomic differences in smoking have generally restricted the measurement of SES to a single indicator. Researchers have therefore attempted to identify an "optimal" indicator of SES by analysing multiple indicators simultaneously, and determining which of them is most strongly related to specific health outcomes. However, a consistent "optimal" indicator has not emerged from this line of inquiry, ${ }^{26}{ }^{27}$ suggesting that socioeconomic conditions shape environmental contexts for smoking and other health risks through several pathways. ${ }^{28}$ Therefore, investigation of multiple indicators of SES remains important to determine the origins of SES differences in smoking.

This study extends the existing literature on SES and smoking in three respects. Firstly, we investigate the association between SES and transitions through specific stages of cigarette use. These are: never use to first use, first use to regular use, and regular use to cessation. Secondly, we compare the separate and combined effects of childhood and adult SES on these three stages. Thirdly, we consider the influences of several indicators of SES on cigarette use.

\section{METHODS}

Subjects were offspring of mothers enrolled in the Providence, Rhode Island-Brown University site of the National Collaborative Perinatal Project (NCPP), ${ }^{29}$ a multisite cohort that entailed the prospective observation and examination of over 50000 pregnancies through the first seven years of life. Obstetrical intake occurred between 1959 and 1966.

From the 4140 Providence NCPP pregnancies, 1057 offspring were selected for participation in an adult follow up study. ${ }^{30}{ }^{31}$ As the original aim of the follow up study was to investigate the adult consequences of childhood learning disabilities, the baseline NCPP cohort was stratified according to the presence or absence of suspected learning disabilities, and subjects were selected randomly within strata. The sample selected for follow up to adulthood was similar to the baseline NCPP cohort with respect to maternal education and parental occupation, although the prevalence of household poverty was slightly higher in the follow up sample $(58.7 \%)$ than in the baseline NCPP sample (49.5\%). Informed consent was obtained from the parents of study participants upon their enrolment in the original NCPP, and from the study participants themselves before their participation in the adult follow up study.

Childhood SES was obtained via detailed social history interviews that were administered to NCPP participants upon enrolment and again when NCPP offspring were age 7 . This was based on maternal education, parental occupation, and household poverty status. Maternal education was coded in years. Parental occupation at the time of the respondent's birth and 7th year was defined as either manual or nonmanual according to 1960 United States census categories. ${ }^{32}$ Subjects in two parent households were assigned to the 
higher occupational category of both parents, whereas those from one parent households were assigned to the occupational category of the parent with whom they were living. Subjects with parents outside of the paid labour force at the time of either childhood assessment were categorised as "not employed". Household poverty status was defined according to the United States federal poverty threshold. ${ }^{33}$ Adult SES was based on respondent's own educational attainment, coded in years, and occupational category based on the United States census in three categories: (1) unskilled or semi-skilled manual; (2) skilled manual; or (3) non-manual. Income was not included in the analysis of adult SES due to missing data.

Cigarette use was based on items from the smoking module of the Diagnostic Interview Schedule (DIS), administered to subjects in adulthood by trained interviewers. ${ }^{34}$ Transitions through stages of cigarette use were assessed via retrospectively reported ages at initiation, regular use, and cessation. Age at initiation was defined as the age at first cigarette, and was obtained for all participants reporting lifetime cigarette use. Among these respondents, progression to regular use was defined as the age at which respondents first smoked daily for $\geqslant 1$ month. Among regular users, individuals whose last half pack of cigarettes was $>1$ year before interview were coded as ex-smokers, and age at smoking cessation was therefore the age at last half pack.

Discrete time survival analysis was used to model the ages at initiation, progression to regular use, and cessation. ${ }^{35} 36$ Three separate analyses were conducted, each one based on the individuals at risk for the three transitions of cigarette use. The full sample was included in the model for initiation, whereas the models for regular use and cessation were based on the subsets of respondents who initiated and became regular users respectively. Similarly, each model incorporated the number of years each person was at risk for progressing to the next transition. Person years from respondents not progressing to the next stage of smoking (that is, those who did not initiate, did not progress to regular smoking, or did not quit smoking) were censored at the age of the follow up interview. All models included indicator variables representing the sample selection factors, and the models for regular use and cessation included the ages at prior transitions. Sex, race/ethnicity, history of maternal smoking, and the age at follow up interview were included as covariates in adjusted analyses.

\section{RESULTS}

Of the 1057 Providence-NCPP offspring selected for participation in the adult follow up study, 720 were successfully located and interviewed (68.1\%). Participation did not vary significantly by childhood socioeconomic status; however, women $(74.4 \%)$ were more likely to participate in the follow up study than men $(64.8 \%)$. The present investigation is based on the 657 subjects (91.3\% of the interviewed sample) with complete data for all study variables. The mean (SD) age of respondents at the time of the adult interview was 33.6 (1.8) (range: 30 to 39). The patterns of cigarette uptake, regular use, and cessation in the full sample and by sex, race/ ethnicity, and SES are presented in table 1. There was a consistent pattern of association between indicators of lower SES across the life course and increased likelihood of initiation and progression to regular use, and decreased likelihood of cessation.

Transitions of cigarette use in the Providence-NCPP Most respondents reported lifetime cigarette use $(80.7 \%$, $n=530)$, most of whom became regular smokers $(79.2 \%$, $\mathrm{n}=420$ ). About one quarter of regular smokers were no longer smoking in the year before interview $(23.1 \%, n=97)$.

\section{Key points}

- Although cigarette smoking has been declining in recent decades, socioeconomic inequalities in smoking persist, and seem to be widening.

- Investigating the influence of socioeconomic status over the life course on specific stages of tobacco use may yield important information on the origins and persistence of socioeconomic inequalities in smoking.

- We analysed data from a prospective study of participants in the Providence, Rhode Island cohort of the United States National Collaborative Perinatal Project, and observed a significant association between lower socioeconomic status in early childhood and the likelihood of smoking initiation. Childhood and adult socioeconomic status contributed to the risk of progression to regular smoking and to the likelihood of smoking cessation.

- The influence of socioeconomic status on persistent smoking accumulates over the lifespan.

The pattern of these transitions over the life course is shown in parts A and B of figure 1. First cigarette use occurred almost entirely during childhood and adolescence, with progression to regular smoking occurring quickly afterward. Initiation of smoking and progression to regular use rarely occurred after age 25 .

These age distributions determined the indicators of childhood and adult SES that were included in the prediction models for each stage of cigarette use. All three indicators of childhood (that is, parental) SES were included in the analysis of initiation. In addition, we included one indicator of adult SES (educational attainment) in the analysis of progression to regular use, and both indicators of adult SES (educational attainment and occupation) in the analysis of cessation. These decisions follow from research showing that attained SES is not established until the second decade of life, that education is the most reliable indicator of attained SES among younger adults, and that occupation-itself heavily influenced by years of education-becomes a reliable indicator of SES later in adulthood. ${ }^{28} 37$

\section{Socioeconomic background and initiation of cigarette use}

In separate models for each indicator of childhood SES, lower SES was associated with increased risk of first cigarette use (table 2). When indicators of childhood SES were included in a single model along with sociodemographic covariates, lower parental occupation, and household poverty remained significantly related to subsequent risk of initiation.

\section{Life course SES and progression to regular smoking}

Indicators of lower childhood and adult SES were significantly related to an increased likelihood of progression to regular use when analysed individually (table 3). Analysed together, only maternal education predicted regular smoking, with each additional year of education conferring a reduction in risk for progression. Respondent's own educational attainment was related to regular smoking in a similar fashion.

\section{Life course SES and smoking cessation}

All indicators of childhood and adult SES were individually related to the likelihood of smoking cessation (Table 4). However, only poverty status during the first seven years of 
Table 1 Cigarette use in the Providence-National Collaborative Perinatal Project follow up sample according to socioeconomic status over the life course $(n=657)$

\begin{tabular}{|c|c|c|c|c|c|c|c|c|}
\hline & \multirow{2}{*}{\multicolumn{2}{|c|}{$\begin{array}{l}\text { Distribution of adult } \\
\text { and childhood factors }\end{array}$}} & \multicolumn{6}{|c|}{ Stages of cigarette use } \\
\hline & & & \multicolumn{2}{|c|}{$\begin{array}{l}\text { Lifetime cigarette use in } \\
\text { the entire sample* }\end{array}$} & \multicolumn{2}{|c|}{$\begin{array}{l}\text { Regular use among subjects } \\
\text { with lifetime uset }\end{array}$} & \multicolumn{2}{|c|}{$\begin{array}{l}\text { Smoking cessation among } \\
\text { regular users } \ddagger\end{array}$} \\
\hline & $\%$ & $\mathbf{N}$ & $\%$ & $\mathbf{N}$ & $\%$ & $N$ & $\%$ & $\mathbf{N}$ \\
\hline \multicolumn{9}{|l|}{ Demographic characteristics } \\
\hline \multicolumn{9}{|l|}{ Sex } \\
\hline Male & 61.2 & 402 & 76.6 & 308 & 77.6 & 239 & 24.7 & 56 \\
\hline Female & 38.8 & 255 & 87.1 & 222 & 81.5 & 181 & 24.6 & 41 \\
\hline \multicolumn{9}{|l|}{ Race/ethnicity } \\
\hline White & 73.8 & 485 & 80.0 & 388 & 80.2 & 311 & 23.7 & 70 \\
\hline Non-white & 26.2 & 172 & 82.6 & 142 & 76.8 & 109 & 27.6 & 27 \\
\hline \multicolumn{9}{|l|}{$\begin{array}{l}\text { Adult socioeconomic status } \\
\text { Educational attainment }\end{array}$} \\
\hline $0-11$ years & 18.0 & 118 & 90.7 & 107 & 94.4 & 101 & 8.3 & 8 \\
\hline 12 years & 34.1 & 224 & 82.1 & 184 & 84.8 & 156 & 20.8 & 30 \\
\hline $13-15$ years & 36.2 & 238 & 79.0 & 188 & 73.4 & 138 & 35.6 & 47 \\
\hline 16+years & 11.7 & 77 & 66.2 & 51 & 49.0 & 25 & 54.6 & 12 \\
\hline \multicolumn{9}{|l|}{ Occupation } \\
\hline Unskilled, semiskilled manual & 34.1 & 224 & 83.5 & 187 & 83.4 & 156 & 16.0 & 24 \\
\hline Skilled manual & 47.5 & 312 & 82.4 & 257 & 82.9 & 213 & 25.1 & 49 \\
\hline Non-manual & 18.4 & 121 & 71.1 & 86 & 59.3 & 51 & 50.0 & 24 \\
\hline \multicolumn{9}{|l|}{ Childhood socioeconomic status } \\
\hline \multicolumn{9}{|l|}{ Maternal educational attainment } \\
\hline $0-8$ years & 21.2 & 139 & 86.3 & 120 & 87.5 & 105 & 17.8 & 18 \\
\hline $9-11$ years & 48.4 & 318 & 81.1 & 258 & 82.6 & 213 & 20.8 & 41 \\
\hline 12 years & 19.9 & 131 & 77.9 & 102 & 72.5 & 74 & 34.8 & 24 \\
\hline $13+$ years & 10.5 & 69 & 72.5 & 50 & 56.0 & 28 & 51.9 & 14 \\
\hline \multicolumn{9}{|c|}{ Parental occupation at subject's birth and 7th year } \\
\hline Birth $\quad$ Age 7 & & & & & & & & \\
\hline Manual & 39.3 & 258 & 86.0 & 222 & 83.3 & 185 & 20.5 & 36 \\
\hline Not employed at birth or age 7 & 21.5 & 141 & 86.5 & 122 & 82.8 & 101 & 15.8 & 15 \\
\hline Manual Non-manual & 10.4 & 68 & 79.4 & 54 & 75.9 & 41 & 35.9 & 14 \\
\hline Non-manual & 10.2 & 67 & 71.6 & 48 & 75.0 & 36 & 32.3 & 10 \\
\hline Non-manual Non-manual & 18.7 & 123 & 68.3 & 84 & 67.9 & 57 & 41.5 & 22 \\
\hline \multicolumn{9}{|c|}{ Household below US poverty level between subject's birth and 7th year } \\
\hline Yes & 56.3 & 370 & 86.2 & 319 & 83.7 & 267 & 19.2 & 48 \\
\hline No & 43.7 & 287 & 73.5 & 211 & 72.5 & 153 & 34.3 & 49 \\
\hline
\end{tabular}

life was related to cessation in a combined analysis of childhood socioeconomic indicators. After adult SES was added into the analysis, the association between childhood poverty and the odds of cessation was slightly attenuated. Furthermore, each additional year of adult education was related to a higher odds of quitting.

\section{DISCUSSION}

In this study we investigated the development of socioeconomic differences in smoking along three axes. Firstly, we considered the influence of SES on the transitions through specific stages of cigarette use, and found that lower SES is significantly related to: (1) increased risk of initiation; (2) increased risk of progression to regular use; and (3) decreased likelihood of cessation. Secondly, we compared the influences of childhood and adult SES on smoking, and found that childhood SES (that is, parental SES) was significantly related to all three stages of cigarette use. In addition, adult SES significantly predicted regular use and cessation. Thirdly, we analysed the associations between multiple indicators of SES and cigarette use, and found that the indicators of childhood SES that were associated with
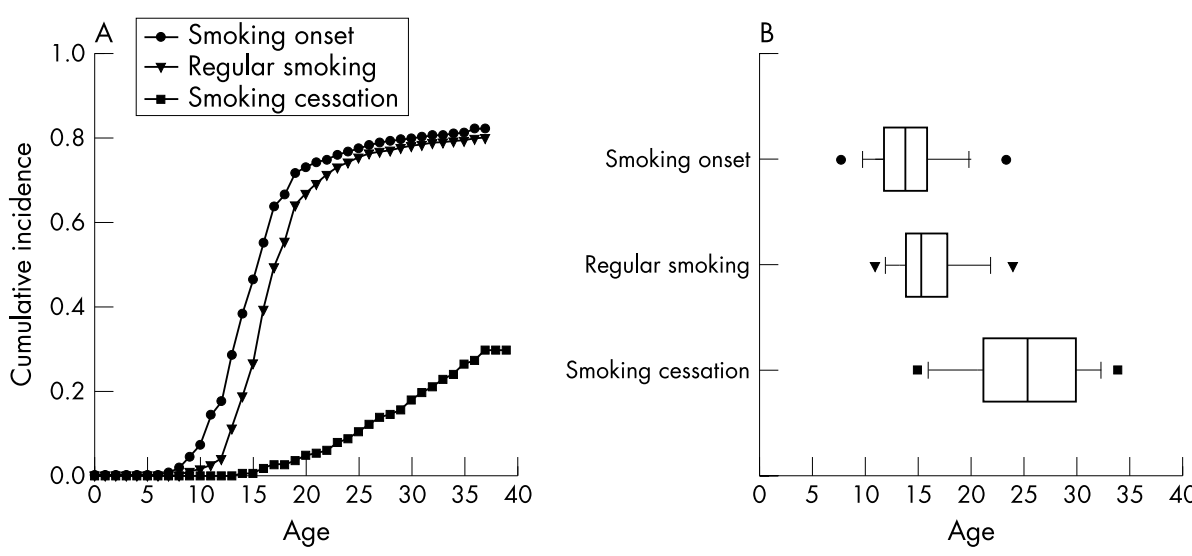

Figure 1 (A) Cumulative incidence of smoking onset, progression to regular smoking, and smoking cessation. (B) Box plots depicting the age distribution of each stage of cigarette use. The symbols outside of each box represent the 5th and 95th centiles, and the line inside each box indicates the median. Median age at first cigarette use $=14.0$, progression to regular smoking $=15.5$, and smoking cessation $=25.0$. 
Table 2 Socioeconomic background and initiation of cigarette use*

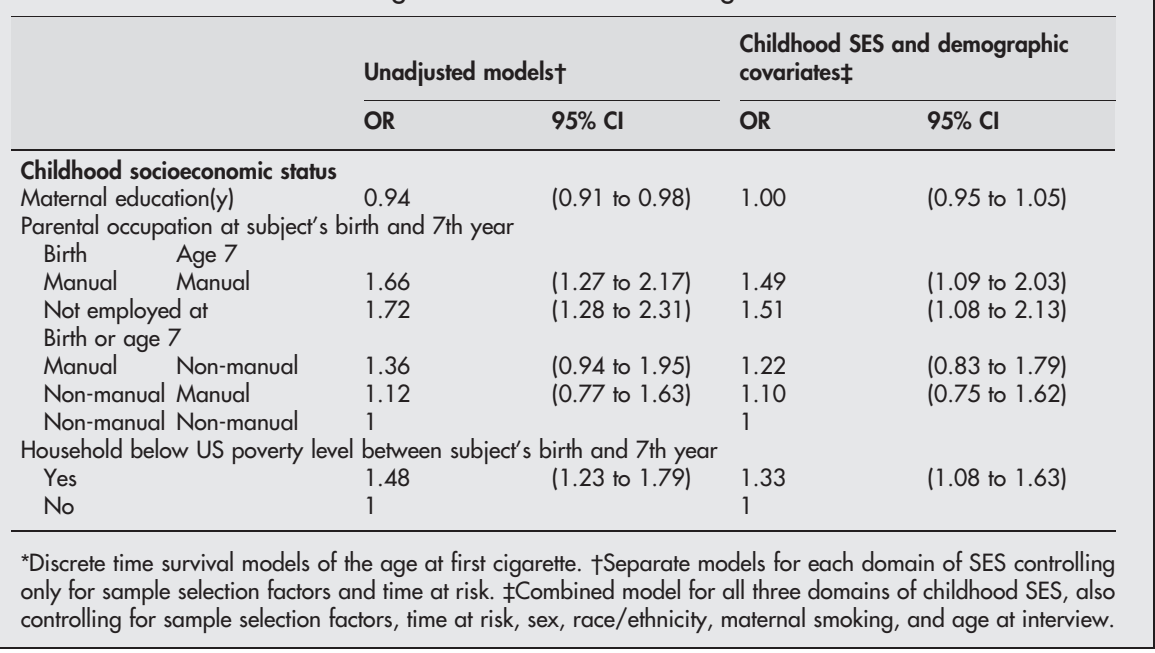

smoking were different for each stage of use; however, adult educational attainment was the dimension of adult SES consistently associated with regular use and cessation. Below we discuss the results pertaining to each of these axes in turn, but first note several limitations to this study.

Our analyses rely on the accuracy of subjects' recollection of the ages at which transitions of cigarette use occurred. The reliability of the DIS age of onset questions has been assessed, yielding acceptable results. ${ }^{38} 39$ The validity of self reported smoking in non-clinical samples is also supported by a high correspondence with serum cotinine concentrations. ${ }^{40} 41$

Our analysis of cessation is limited by the lack of data on patterns of all quit attempts following the onset of regular smoking. Rather, we focused on "current ex-smokers" - that is, people who were not smoking in the year before interview. Our use of a one year definition of remission means that people classified as having quit smoking will probably experience sustained abstinence, given that relapse rates drop sharply after one year of remission. ${ }^{42}$ We were also not able to investigate the influence of respondents' income as adults on the stages of cigarette use. This may account for part of the association between educational attainment and progression to regular smoking as well as smoking cessation.
The Providence-NCPP was conducted contemporaneously with downward secular trends in cigarette use. As described above, however, declines in cigarette uptake and increases in cessation over the past 30 years have been most prominent among higher SES people. Within the context of a single birth cohort though, it is not possible to distinguish period/ historical from cohort/generational effects. ${ }^{43}{ }^{44}$ However, the long term follow up of a birth cohort such as the ProvidenceNCPP allows for the linkage of childhood conditions to adult heath without the reliance on retrospective reports of the childhood environment. What is therefore needed is the investigation of life course SES in successive cohorts so as to evaluate the combined effects of secular trends and individual risk factors. Of note, Osler et al observed widening SES differences in current and lifetime smoking among younger birth cohorts, raising the possibility that the effects of SES within individuals over time are increasing contemporaneously with steeper socioeconomic gradients in smoking across individuals. ${ }^{45}$

\section{SES and smoking initiation, progression to regular use, and cessation}

People of lower SES were more likely to start smoking, more likely to become regular smokers, and less likely to quit.

Table 3 Socioeconomic background, adult SES, and progression to regular smoking*

\begin{tabular}{|c|c|c|c|c|c|c|}
\hline & \multicolumn{2}{|c|}{ Unadjusted models $†$} & \multicolumn{2}{|c|}{$\begin{array}{l}\text { Childhood SES, demographic } \\
\text { controls } \ddagger\end{array}$} & \multicolumn{2}{|c|}{$\begin{array}{l}\text { Childhood SES, demographic } \\
\text { controls, adult SES§ }\end{array}$} \\
\hline & OR & $95 \% \mathrm{Cl}$ & OR & $95 \% \mathrm{Cl}$ & OR & $95 \% \mathrm{Cl}$ \\
\hline \multicolumn{7}{|l|}{ Childhood socioeconomic status } \\
\hline Maternal education (y) & 0.88 & (0.84 to 0.91$)$ & 0.88 & (0.83 to 0.93 ) & 0.91 & $(0.86$ to 0.97$)$ \\
\hline \multicolumn{7}{|c|}{ Parental occupation at subject's birth and 7th year } \\
\hline Age 7 & & & & & & \\
\hline Manual & 1.94 & $(1.40$ to 2.70$)$ & 1.12 & $(0.75$ to 1.68$)$ & 0.82 & $(0.54$ to 1.25$)$ \\
\hline & \multicolumn{6}{|c|}{ birth or age 7} \\
\hline Manual Non-manual & 1.40 & $(0.90$ to 2.17$)$ & 1.05 & (0.64 or 1.71$)$ & 0.83 & $(0.51$ to 1.37$)$ \\
\hline Non-manual Manual & 1.36 & $(0.86$ to 2.15$)$ & 1.00 & (0.61 to 1.63 ) & 0.84 & $(0.51$ to 1.39$)$ \\
\hline Non-manual Non-manual & 1 & & 1 & & 1 & \\
\hline \multicolumn{7}{|c|}{ Household below US poverty level between subject's birth and 7th year } \\
\hline Yes & 1.51 & $(1.21$ to 1.88$)$ & 1.27 & (0.99 to 1.64$)$ & 1.22 & $(0.95$ to 1.58$)$ \\
\hline No & 1 & & 1 & & 1 & \\
\hline \multicolumn{7}{|l|}{ Adult socioeconomic status } \\
\hline Educational attainment (y) & 0.77 & (0.73 to 0.82 ) & & & 0.82 & (0.77 to 0.87 ) \\
\hline
\end{tabular}


Table 4 Socioeconomic background, adult socioeconomic status, and smoking cessation*

\begin{tabular}{|c|c|c|c|c|c|c|}
\hline & Unad & & $\begin{array}{l}\text { Childh } \\
\text { contro }\end{array}$ & SES, demographic & $\begin{array}{l}\text { Childh } \\
\text { contro }\end{array}$ & $\begin{array}{l}\text { SES, demographic } \\
\text { dult SES§ }\end{array}$ \\
\hline & OR & $95 \% \mathrm{Cl}$ & OR & $95 \% \mathrm{Cl}$ & OR & $95 \% \mathrm{Cl}$ \\
\hline Childhood socioeconomic status & & & & & & \\
\hline Maternal education $(y)$ & 1.20 & (1.09 to 1.31$)$ & 1.10 & (0.99 to 1.24$)$ & 1.03 & (0.92 to 1.15$)$ \\
\hline Parental occupation at subject's & rth and & & & & & \\
\hline Age 7 & & & & & & \\
\hline Manual Manual & 0.43 & (0.25 to 0.74$)$ & 0.68 & $(0.36$ to 1.32$)$ & 0.83 & (0.41 to 1.66$)$ \\
\hline $\begin{array}{l}\text { Not employed at } \\
\text { birth or age } 7\end{array}$ & 0.33 & (0.17 to 0.64$)$ & 0.57 & $(0.26$ to 1.26$)$ & 0.66 & $(0.29$ to 1.50$)$ \\
\hline Manual Non-manual & 0.77 & (0.39 to 1.54$)$ & 1.00 & (0.48 to 2.09$)$ & 1.06 & (0.50 to 2.27$)$ \\
\hline Non-manual Manual & 0.73 & (0.34 to 1.57 ) & 0.89 & $(0.40$ to 2.00$)$ & 0.93 & $(0.40$ to 2.16$)$ \\
\hline Non-manual Non-manual & 1 & & 1 & & 1 & \\
\hline Household below US poverty lev & betwee & oirth and 7th yea & & & & \\
\hline Yes & 0.52 & (0.35 to 0.78$)$ & 0.62 & $(0.40$ to 0.98$)$ & 0.68 & (0.42 to 1.08$)$ \\
\hline No & 1 & & 1 & & 1 & \\
\hline Adult socioeconomic status & & & & & & \\
\hline Educational attainment $(y)$ & 1.38 & (1.24 to 1.53 ) & & & 1.25 & (1.12 to 1.41$)$ \\
\hline Occupation & & & & & & \\
\hline Unskilled, semiskilled manual & 0.24 & $(0.13$ to 0.43$)$ & & & 0.51 & (0.25 to 1.01$)$ \\
\hline Skilled manual & 0.41 & (0.25 to 0.68$)$ & & & 0.68 & (0.38 to 1.21$)$ \\
\hline Non-manual & 1 & & & & 1 & \\
\hline
\end{tabular}

These findings are consistent with prior analyses of prevalent smoking $^{811}$ as well as analyses of individual stages of cigarette use (that is, initiation ${ }^{21}$ and cessation $^{46}{ }^{47}$ ), and underscore the importance of directing interventions towards multiple stages of use for the purpose of reducing socioeconomic differentials in smoking. This includes the prevention of cigarette uptake among disadvantaged youth, ${ }^{2}$ and improving access to smoking cessation programmes among lower SES adults. ${ }^{48-50}$ The comparative lack of information on the efficacy of smoking cessation programmes among lower SES individuals and among racial minorities is especially notable in light of the increasing need for such programmes. $^{48}$

\section{SES across the life course and cigarette use}

Lower parental SES during the first seven years of life increased the risk of first cigarette use. Subsequently, lower parental SES as well as a person's own SES significantly increased the likelihood of progression to regular use. Smokers from lower socioeconomic backgrounds and those with lower attained SES were also least likely to quit. The combined effects of childhood and adult SES on the odds of daily cigarette use suggest that risk for persistent smoking is increased sharply in the context of life course socioeconomic disadvantage. With respect to smoking cessation, we observed that adult SES partly accounted for the reduced odds of cessation among respondents who experienced poverty during their childhood. This highlights the relevance of SES trajectories over the life course for adult smoking. ${ }^{51}$

Among adults, indicators of low SES are consistently related to a decreased likelihood of cessation. ${ }^{52}$ However, evidence in support of an association between childhood SES and adult smoking is inconsistent. In the Whitehall II study of British civil servants, for example, Brunner et al found that father's social class predicted current smoking independently from respondents' own social class; however, this was significant only among women. ${ }^{53}$ Other studies failed to find any effect of father's SES on current smoking net of adult SES. ${ }^{54-56}$ However, these studies assessed childhood SES using retrospective reports from adult respondents, and analysed current smoking rather than stages of cigarette use..$^{57}$

\section{Policy implications}

- Social and economic policies should be considered as a potential avenue for tobacco control.

- Addressing socioeconomic inequalities in smoking will be important for reducing the prevalence of smoking in the population as a whole.

\section{Multiple dimensions of childhood and adult SES}

Although the results of our study and those of previous studies demonstrate a persistent relation between lower SES and stages of cigarette use, there is considerable variability across studies in the dimensions of SES that are most important for smoking outcomes. In our analyses, all of the indicators of childhood SES and adult SES were significantly correlated with transitions through stages of cigarette use when analysed individually. When modelled simultaneously though, parental occupation was predictive only of initiation, maternal education predicted progression to regular smoking, and household poverty during childhood predicted initiation along with cessation.

It is not immediately clear why the measures of childhood SES that predict smoking are different for initiation, regular use, and cessation. Keeping in mind the fact that indicators of SES are subject to measurement error, various dimensions of childhood SES probably represent different aspects of children's socioeconomic conditions. Interestingly, Harper et al proposed that parental education reflects children's intellectual environment whereas parental occupation and income reflect children's access to material resources. ${ }^{58}$ Although direct tests of these hypotheses are needed, ${ }^{59}$ extending Harper et al's theory to the present results suggests that factors related to material disadvantage may explain the association between parental SES and smoking initiation, whereas factors related to cognition or cognitive development may contribute to the habitualisation of cigarette use among lower SES experimenters. ${ }^{60}$

Regarding adult SES, respondent's own education, but not occupation, strongly predicted progression to regular use and 
cessation. Similarly, results from previous studies that analysed multiple indicators of adult SES also suggest that adult educational attainment is more closely aligned with smoking than occupation or income. ${ }^{426}$ However, evidence also exists to suggest that education, occupation, and income contribute independently to smoking risk..$^{1156}$

Although indicators of SES tend to be highly correlated, they are not entirely redundant, ${ }^{26}$ suggesting that SES is not a unidimensional construct but reflects multiple social processes that may be of varying importance for different health outcomes. ${ }^{28}$ Therefore, to further investigate the association between SES and cigarette use, we would argue for the continued analysis of multiple measures of SES in future studies-rather than empirically selecting a single indicator of $\mathrm{SES}^{27}{ }^{61}$ - So as to permit the conceptual work necessary to link specific aspects of SES to aetiological processes.

\section{Conclusion}

The relation between SES and smoking patterns is complex, involving cumulative and multiple effects across the human life course, possibly extending from one generation to the next. Therefore, social and economic policies may have significant implications for tobacco use and should be considered a potential avenue for tobacco control. ${ }^{62}$ Taking a transdisciplinary perspective to understanding patterns of variation in smoking across the life course indicates how results of studies like this one have the potential to inform future interventions and policy formation towards long term strategies for systematically reducing population smoking prevalence and associated disease burden..$^{63}$

\section{ACKNOWLEDGEMENTS}

This research was presented in part at the Society for Epidemiologic Research, Palm Desert, California, June 2002. The authors thank Dr Brian Hitsman, Dr Richard Rende, and Dr Edmond Shenassa for their helpful comments on an earlier version of this manuscript.

\section{Authors' affiliations}

S E Gilman, D B Abrams, Centers for Behavioral and Preventive Medicine, Brown Medical School and The Miriam Hospital, Providence, USA

S L Buka, Departments of Maternal and Child Health and Epidemiology, Harvard School of Public Health, Boston, USA

Funding: support for this research was received from the National Cancer Institute, Transdisciplinary Tobacco Use Research Center Grant P50 CA84719, and from the National Institute of Mental Health, Grant MH61953. Additional funding was provided by the National Institute on Drug Abuse and the Robert Wood Johnson Foundation.

Conflicts of interest: none declared.

\section{REFERENCES}

1 Giovino GA, Henningfield JE, Tomar SL, et al. Epidemiology of tobacco use and dependence. Epidemiol Rev 1995;17:48-65.

2 Escobedo LG, Anda RF, Smith PF, et al. Sociodemographic characteristics of cigarette smoking initiation in the United States. Implications for smoking prevention policy. JAMA 1990;264:1550-5.

3 Anthony JC, Warner LA. Comparative epidemiology of dependence on tobacco, alcohol, controlled substances, and inhalants: basic findings from the National Comorbidity Survey. Exp Clin Psychopharmacol 1994; 2:244-68.

4 Wagenknecht LE, Perkins LL, Cutter GR, et al. Cigarette smoking behavior is strongly related to educational status: the CARDIA study. Prev Med 1990; 19:158-69.

5 Iribarren C, Luepker RV, McGovern PG, et al. Twelve-year trends in cardiovascular disease risk factors in the Minnesota Heart Survey. 1997;157:873-81.

6 Nelson DE, Emont SL, Brackbill RM, et al. Cigarette smoking prevalence by occupation in the United States. A comparison between 1978 to 1980 and 1987 to 1990. J Occup Med 1994;36:516-25.

7 Pierce JP, Fiore MC, Novotny TE, et al. Trends in cigarette smoking in the United States. Educational differences are increasing. JAMA 1989:261:56-60.
8 Osler M, Gerdes LU, Davidsen M, et al. Socioeconomic status and trends in risk factors for cardiovascular diseases in the Danish MONICA population, 1982-1992. J Epidemiol Community Health 2000;54:108-13.

9 Zhu BP, Liu M, Shelton D, et al. Cigarette smoking and its risk factors among elementary school students in Beijing. Am J Public Health 1996:86:368-75.

10 Stanton WR, Oei TP, Silva PA. Sociodemographic characteristics of adolescent smokers. Int J Addict 1994;29:913-25.

11 Whitlock G, MacMahon S, Vander Hoorn S, et al. Socioeconomic distribution of smoking in a population of 10,529 New Zealanders. N Z Med J 1997;1 10:327-30.

12 Fernandez E, Garcia M, Schiaffino A, et al. Smoking initiation and cessation by gender and educational level in Catalonia, Spain. Prev Med 2001:32:218-23.

13 Hulshof KF, Wedel M, Lowik MR, et al. Clustering of dietary variables and other lifestyle factors (Dutch Nutritional Surveillance System). J Epidemiol Community Health 1992;46:417-24.

14 Pekkanen J, Tuomilehto J, Uutela A, et al. Social class, health behaviour, and mortality among men and women in eastern Finland. BMJ 1995:311:589-93.

15 Cavelaars AE, Kunst AE, Geurts JJ, et al. Educational differences in smoking: international comparison. BMJ 2000;320:1102-7.

16 Townsend J, Roderick P, Cooper J. Cigarette smoking by socioeconomic group, sex, and age: effects of price, income, and health publicity. $B M$ 1994; 309:923-7.

17 Fernandez E, Schiaffino A, Garcia $M$, et al. Widening social inequalities in smoking cessation in Spain, 1987-1997. J Epidemiol Community Health 2001;55:729-30.

18 Bartley M, Fitzpatrick R, Firth $D$, et al. Social distribution of cardiovascular disease risk factors: change among men in England 1984-1993. J Epidemiol Community Health 2000;54:806-14.

19 Bennett S. Cardiovascular risk factors in Australia: trends in socioeconomic inequalities. J Epidemiol Community Health 1995:49:363-72.

20 Fiore MC, Novotny TE, Pierce JP, et al. Trends in cigarette smoking in the United States. The changing influence of gender and race. JAMA 1989;261:49-55.

21 Harrell JS, Bangdiwala SI, Deng S, et al. Smoking initiation in youth: the roles of gender, race, socioeconomics, and developmental status. J Adolesc Health 1998;23:271-9

22 Wallace JM Jr, Forman TA, Guthrie BJ, et al. The epidemiology of alcohol, tobacco and other drug use among black youth. J Stud Alcohol 1999:60:800-9.

23 Breslau N, Peterson EL. Smoking cessation in young adults: age at initiation of cigarette smoking and other suspected influences. Am J Public Health 1996;86:214-20.

24 Chassin L, Presson CC, Rose JS, et al. The natural history of cigarette smoking from adolescence to adulthood: demographic predictors of continuity and change. Health Psychol 1996;15:478-84.

25 Pierce JP, Gilpin E. How long will today's new adolescent smoker be addicted to cigarettes? Am J Public Health 1996;86:253-6.

26 Winkleby $M A$, Jatulis $D E$, Frank $E$, et al. Socioeconomic status and health: how education, income, and occupation contribute to risk factors for cardiovascular disease. Am J Public Health 1992;82:816-20.

27 Duncan GJ, Daly MC, McDonough P, et al. Optimal indicators of socioeconomic status for health research. Am J Public Health 2002;92:1151-7.

28 Berkman LF, Macintyre S. The measurement of social class in health studies: old measures and new formulations. IARC Sci Publ 1997;138:51-64.

29 Niswander KR, Gordon M. The women and their pregnancies: the Collaborative Perinatal Study of the National Institute of Neurological Diseases and Stroke. Washington: National Institute of Health, 1972.

30 Gilman SE, Kawachi I, Fitzmaurice GM, et al. Socioeconomic status in childhood and the lifetime risk of major depression. Int J Epidemiol 2002;31:359-67

31 Buka SL, Satz P, Seidman L, et al. Defining learning disabilities: the role of longitudinal studies. Thalamus 1998:16:14-29.

32 US Bureau of the Census. Methodology and scores of socioeconomic status (working paper no 15), Washington, DC: US Bureau of the Census, 1963.

33 US Bureau of the Census. Weighted average poverty thresholds for families of specified sized: 1959-1998. Washington, DC: US Bureau of the Census, 2000 (http://www.census.gov/hhes/poverty/histpov/hstpovl.html).

34 Robins LN, Helzer JE, Croughan J, et al. National Institute of Mental Health Diagnostic Interview Schedule. Its history, characteristics, and validity. Arch Gen Psychiatry 1981;38:381-9.

35 Cox DR. Regression models and life-tables. Journal of the Royal Statistical Society, Series B (Methodological) 1972;34:187-220.

36 Efron B. Logistic regression, survival analysis, and the Kaplan-Meier curve. Journal of the American Statistical Association 1988:83:415-25.

37 Liberatos P, Link BG, Kelsey JL. The measurement of social class in epidemiology. Epidemiol Rev 1988;10:87-121.

38 Farrer LA, Florio LP, Bruce ML, et al. Reliability of self-reported age at onset of major depression. J Psychiatr Res 1989:23:35-47.

39 Wittchen HU, Burke JD, Semler G, et al. Recall and dating of psychiatric symptoms. Test-retest reliability of time-related symptom questions in a standardized psychiatric interview. Arch Gen Psychiatry 1989;46:437-43.

40 Vartiainen E, Seppala T, Lillsunde P, et al. Validation of self reported smoking by serum cotinine measurement in a community-based study. J Epidemiol Community Health 2002:56:167-70.

41 Wagenknecht LE, Burke GL, Perkins LL, et al. Misclassification of smoking status in the CARDIA study: a comparison of self-report with serum cotinine levels. Am J Public Health 1992;82:33-6.

42 Gilpin EA, Pierce JP, Farkas AJ. Duration of smoking abstinence and success in quitting. J Natl Cancer Inst 1997;89:572-6. 
43 Magnusson D. European Network on Longitudinal Studies on Individual Development. Problems and methods in longitudinal researchstability and change. Cambridge, NY: Cambridge University Press, 1991

44 Menard SW. Longitudinal research. Newbury Park, CA: Sage, 1991.

45 Osler M, Holstein B, Avlund K, et al. Socioeconomic position and smoking behaviour in Danish adults. Scand J Public Health 2001 ;29:32-9.

46 Hyman DJ, Simons-Morton DG, Dunn JK, et al. Smoking, smoking cessation and understanding of the role of multiple cardiac risk factors among the urban poor. Prev Med 1996;25:653-9.

47 Monso E, Campbell J, Tonnesen $\mathrm{P}$, et al. Sociodemographic predictors of success in smoking intervention. Tobacco Control 2001;10:165-9.

48 Benowitz NL. Smoking cessation trials targeted to racial and economic minority groups. JAMA 2002;288:497-9.

49 Niaura R, Abrams DB. Smoking cessation: progress, priorities, and prospectus. J Consult Clin Psychol 2002;70:494-509.

50 Kawachi I, Lochner K. Socioeconomic status. Cancer Causes Control 1997;8(suppl 1):S39-42.

51 Power C, Matthews S. Origins of health inequalities in a national population sample. Lancet 1997:350:1584-9.

52 Flint AJ, Novotny TE. Poverty status and cigarette smoking prevalence and cessation in the United States, 1983-1993: the independent risk of being poor. Tobacco Control 1997;6:14-18.

53 Brunner E, Shipley MJ, Blane D et al. When does cardiovascular risk start? Past and present socioeconomic circumstances and risk factors in adulthood. $J$ Epidemiol Community Health 1999;53:757-64.

54 Greenlund KJ, Liu K, Kiefe Cl, et al. Impact of father's education and parental smoking status on smoking behavior in young adults. The CARDIA study.
Coronary artery risk development in young adults. Am J Epidemiol 1995; 142:1029-33.

55 van de Mheen H, Stronks K, Looman CW, et al. Does childhood socioeconomic status influence adult health through behavioural factors? Int J Epidemiol 1998:27:431-7.

56 Lynch JW, Kaplan GA, Salonen JT. Why do poor people behave poorly? Variation in adult health behaviours and psychosocial characteristics by stages of the socioeconomic lifecourse. Soc Sci Med 1997;44:809-19.

57 Mayhew KP, Flay BR, Mott JA. Stages in the development of adolescent smoking. Drug Alcohol Depend 2000;59(suppl 1):S61-81.

58 Harper S, Lynch J, Hsu WL, et al. Life course socioeconomic conditions and adult psychosocial functioning. Int J Epidemiol 2002;31:395-403.

59 Gilman SE. Childhood socioeconomic status, life course pathways and adult mental health. Int J Epidemiol 2002;31:403-4.

60 McLoyd VC, Wilson L. The strain of living poor: parenting, social support, and child mental health. In: Huston AC, ed. Children in poverty: child development and public policy. Cambridge, UK: Cambridge University Press, 1994:105-35.

61 Davey Smith G, Hart C, Hole D, et al. Education and occupational social class: which is the more important indicator of mortality risk? J Epidemiol Community Health 1998;52:153-60

62 Black D, Morris JN, Smith C, et al. Better benefits for health: plan to implement the central recommendation of the Acheson report. BMJ 1999:318:724-7.

63 Abrams DB. Transdisciplinary paradigms for tobacco prevention research. Nicotine and Tobacco Research 1999;1:S15-23.

64 Abrams DB. Nicotine addiction: paradigms for research in the 21 st century. Nicotine and Tobacco Research 1999:1:S211-15.

\section{APHORISM OF THE MONTH}

\section{The need for strategic underview}

T

op-down, bottom-up, meet in the middle-there is a lot of discussion about how to modernise and achieve change, particularly in public services. We have been inching our way from feudal organisational forms through the free market and paternalistic organisations. The current received wisdom is about the need to empower frontline staff and to shift the balance of power away from the centre towards the periphery. Decentralisation and participation are the key words. There is often talk, rather like sheep and goats, of people who are either "strategic" (visionaries, leaders, high paid people) or "operational" (the people who do the work and are usually much lower paid with much less job security, and who are often sacrificed when things go wrong).

The reality is that, as usual in life, we need a whole systems approach, where we acknowledge and respect our interdependence. This means that not only should the high flying leaders keep their feet on the ground, while maintaining their eyes above the horizon, but that the doers should understand how their contributions, so often considered modest, contribute to major strategic achievements. The need for strategic underview. 